\title{
Eu, pronome oblíquo ${ }^{1}$
}

\author{
Alexandre Nodari*
}

\begin{abstract}
A vida oblíqua? Bem sei que há um desencontro leve entre as coisas, elas quase se chocam, há desencontro entre os seres que se perdem uns aos outros entre palavras que quase não dizem mais nada. Mas quase nos entendemos nesse leve desencontro, nesse quase que é a única forma de suportar a vida em cheio, pois um encontro brusco face a face com ela nos assustaria, espaventaria os seus delicados fios de teia de aranha. Nós somos de soslaio para não comprometer o que pressentimos de infinitamente outro nessa vida de que te falo. (Clarice Lispector)
\end{abstract}

0. As linhas que se seguem são uma tentativa (indireta, oblíqua, transversal) de interlocução com (ou tradução em outra linguagem de) três poemas de André Vallias aqui reproduzidos: ortego (2013), ego (2014) e geo (2015). Na medida em que a poesia de Vallias inter-vém em debates teóricos e políticos, não simplesmente tomando-os como temas (não são poemas sobre assuntos), mas participando deles por meio da elaboração poética, o que implica também a reconfiguração da forma do debate, assim como seu alcance e duração, ou seja, uma interlocução e tradução poéticas, de certa forma o ensaio que segue é também uma interlocução sobre a interlocução, uma tradução (teórica) da operação tradutória de Vallias.

\footnotetext{
${ }^{1} \mathrm{O}$ presente ensaio expande e altera substancialmente um texto publicado em inglês na New Observations, n. 130 (2014), dedicado ao tema da interlocução e organizado por Pedro Paixão, a quem agradeço por ter me estimulado a escrever sobre o assunto e gentilmente autorizado que eu reproduzisse a presente versão (ou variação) em português.

* Professor de Literatura Brasileira e Teoria Literária da UFPR. Co-fundador do species - núcleo de antropologia especulativa.
} 
1. Se há algo que a atual "superprodução semiótica" ${ }^{2}$ nos ensina sobre a interlocução é que ela não consiste numa mera troca de mensagens. Cada vez que pisamos fora de casa, seja "real" seja "virtualmente", somos inundados por uma torrente de mensagens, discursos, informações, imagens, que fazem o mundo parecer uma imensa agência postal, ou mais especificamente, uma seção de cartas extraviadas, como aquela na qual Bartleby trabalhou. Pois, por mais que tenha aumentado o diálogo (e mesmo a dialética, seu equivalente no mundo do saber ocidental), temos a impressão de que aquilo que chamamos de interlocução não cresceu na mesma medida. As pessoas e as entidades (empresas, personagens virtuais, Estados, ONGs, etc.) falam cada vez mais umas com as outras, sem que se estabeleça necessariamente entre elas aquela peculiar transformação que dois interlocutores sentem quando se encontram: sobra comunicação, falta tradução. Mas, se a interlocução não se confunde com a troca de mensagens, no que ela consiste? A nosso ver, trata-se acima de tudo da troca de posições locutórias: desse modo, ela não seria tanto uma esfera comum de troca imediata de conteúdos entre dois seres, mas, antes, a criação de uma zona de inter-esse, de entre-ser, em que há um intercâmbio da posição-sujeito, do "eu", uma locução-entre. Só com essa troca é que há, de fato, entre-locução: $o$ meio é a mensagem, o entre é a interlocução. Não se trata de um diálogo entre dois sujeitos fixos, mas da criação de uma relação que torna possível a translação posicional do "eu" entre dois sujeitos móveis. Dito de outro modo: a interlocução talvez seja a condição de possibilidade da tradução, na medida em que estabelece uma equi-vocidade a cada vez que se diz "eu" (todo ego é também um eco). Pois o que é uma tradução senão um transporte do eu que fala para outra voz, um eco que, como todo eco, não é apenas repetição, mas também diferimento? Nesse sentido, o equívoco (e a transformação resultante), e não o entendimento (e a identidade que dele deriva), seria a condição interlocutória e tradutória por excelência: "O equívoco", diz Eduardo Viveiros de Castro, "não é o que impede a relação, mas aquilo que a funda e a propele: uma diferença de perspectiva. Traduzir é presumir que há desde sempre e para sempre um equívoco; é comunicar pela diferença,

${ }^{2}$ Cf. Durão, Fábio Akcelrud. “Da superprodução semiótica: caracterização e implicações estéticas.” Em: Durão, F. A.; Zuin, A.; Vaz, A. F. A indústria cultural hoje. São Paulo: Boitempo, 2008. pp. 39-48. 
em vez de silenciar o Outro ao presumir uma univocidade originária e uma redundância última - uma semelhança essencial". ${ }^{3}$ O interlocutor não é simplesmente um outro "eu" com quem dialogo (um "tu"), mas aquele que assume temporariamente a minha própria posição de "eu" (e vice-versa): um como eu, que faz de mim, nesse mesmo gesto, um como outro. Na interlocução (na tradução), a diferença (o eco) é constitutiva à voz que diz eu (o ego).

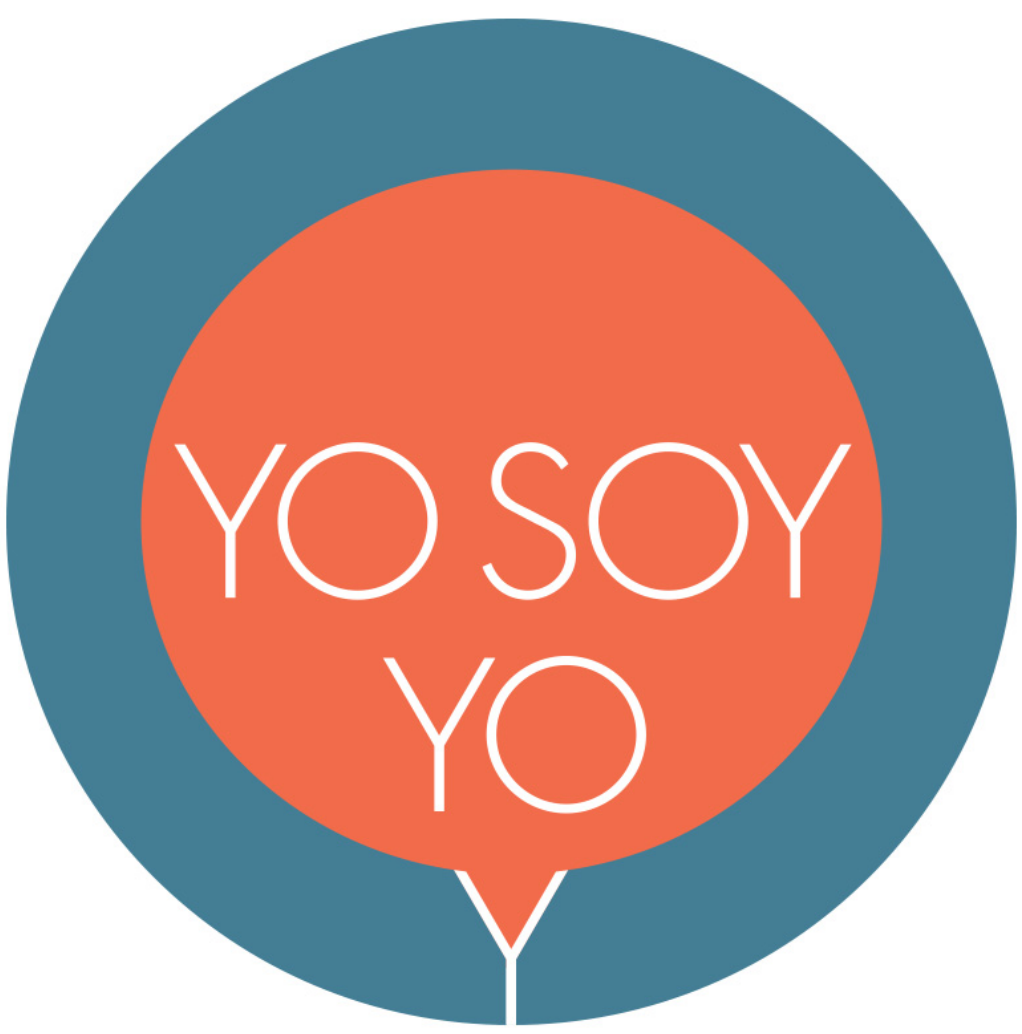

Ortego - André Vallias (2013)

\footnotetext{
${ }^{3}$ Viveiros de Castro, Eduardo. Metafísicas canibais: elementos para uma antropologia pós-estrutural. São Paulo: Cosac Naify / n-1 edições, 2015. p. 91.
} 
2. Ortega y Gasset precisou esse estranho estatuto da interlocução de forma magistral: "Que queremos dizer quando dizemos que temos diante nós Outro, isto é, outro como eu (...)? Isso implica que esse novo ser (...) é um eu, ego, mas, ao mesmo tempo, é outro, alter, é um alter ego (...). Um eu que não sou eu, mas que é precisamente outro, portanto, não-eu". ${ }^{4}$ Assim, o que o alter ego mostra a mim, a ego, é a existência de "um mundo alheio ao meu, um outro mundo" ${ }^{5}$ no qual sou objeto, no qual o eu é um outro. Como lembra Daniel Heller-Roazen, segundo a hipótese de Karl Brugmann, "o termo grego ego, assim como seus correlatos no indo-europeu, derivaria de um substantivo neutro ( ${ }^{*} e g[h]$ om), que significaria simplesmente 'aquiedade' (Hierheit), de modo que, originalmente, 'eu' teria o sentido de ser insubstancial de qualquer coisa que fosse indicada como 'aqui', fosse ela animada ou inanimada, humana ou inumana, sua expressão falada ou escrita". ${ }^{6} \mathrm{O}$ "eu", desse modo, seria um dêitico (o dêitico dos dêiticos, poderíamos dizer), a marcação por excelência da posição locucionária, do lugar de onde se fala, ou melhor, do mundo de onde se fala ("O cosmos parte do eu", diria Oswald de Andrade): trata-se de uma perspectiva, mas não uma perspectiva sobre o mundo ("mundo-para-um-sujeito"), e sim a perspectiva de um mundo ("mundo-de-um-sujeito"), para retomar uma diferenciação fundamental entre relativismo e perspectivismo de Déborah Danowski e Eduardo Viveiros de Castro. ${ }^{7}$ Diante de um outro como eu, de um alter ego, abrese, para usar a belíssima formulação de Clarice Lispector, uma zona "tão volátil e quase inexistente que fica entre mim e eu" ${ }^{\prime \prime}$, entre o eu como sujeito e o mim como objeto. É esse espaço que torna toda interlocução e toda tradução possíveis: a diferença entre o sujeito (eu) e sua forma oblíqua (mim), e a possibilidade de passar de uma posição a outra, i.e., a possibilidade de obliquação9, de habitar um outro mundo. A "tarefa do tradutor" não seria

\footnotetext{
${ }^{4}$ Ortega y Gasset, José. O homem e a gente: inter-comunicação humana. 2. ed. Tradução de J. Carlos Lisboa. Rio de Janeiro: Livro Ibero-Americano Ltda, 1973. p. 155.

5 Ibid., p. 156.

${ }^{6}$ Heller-Roazen, Daniel. Ecolalias. Tradução de Fábio Durão. Campinas: Ed. da UNICAMP, 2010. p. 135.

7 Danowski, Déborah; Viveiros de Castro, Eduardo. Há mundo por vir? Ensaio sobre os medos e os fins. Desterro: Cultura e Barbárie; ISA, 2014. p. 33.

${ }^{8}$ Lispector, Clarice. Água viva. Rio de Janeiro: Rocco, 1998. p. 20.

${ }^{9}$ Como se vê, a noção de obliquação (a passagem do eu ao mim) é inspirada em Clarice; cf., para uma primeira aproximação, Nodari, Alexandre. “O hetairismo ontológico segundo G.H.". O eixo e a roda, 24
} 
assim a de recriar o texto, mas o mundo de que este fala: em última instância, em uma tradução, o texto permanece idêntico, se repete; o que muda, o que difere, é todo resto - o mundo. Nesse sentido, a tradução é uma composição de mundos, em que o encontro de alter egos faz com que se transformem reciprocamente, se outrem, troquem de mundos.

3. Uma das esculturas mais conhecidas de Maria Martins, chamada Impossible, parece colocar em cena justamente tal encontro oblíquo: "dois corpos, um feminino e um masculino, são impedidos de se aproximar totalmente em função das estranhas formas pontiagudas de suas cabeças", descreve Veronica Stigger, "ao mesmo tempo em que parecem magneticamente amorosamente - ligados para sempre". Essas "estranhas formas pontiagudas"10, que parecem até mesmo ocupar o lugar da cabeça desses dois corpos, portanto, acéfalos, são como que dentes disformes que fazem das (faltas de) cabeças puras bocas - lugar da absorção e da emissão, da devoração e da fala. A boca que fala é a mesma que mastiga: uma boca aberta é sempre sinal de perigo. Tais dentições informes criam, desse modo, um entrela-

(2015): 139-154, de onde retomo alguns pontos. Por motivos que tentarei desenvolver em trabalhos posteriores (e já prefigurados "A literatura como antropologia especulativa". Revista da ANPOLL, 38 (2015): 75-85), a literatura (ou a arte em geral) aparece como espaço privilegiado, no Ocidente, em que a obliquação se torna experienciável, muitas vezes por meio de sua auto-tematização. Veja-se, por exemplo, "eupoema", de Décio Pignatari (Poesia pois é poesia: 1950-2000. Cotia; Campinas: Ateliê Editorial; Editora da UNICAMP, 2004. p. 53):

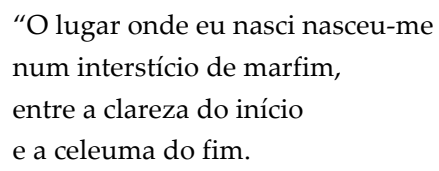

Eu jamais soube ler: meu olhar

de errata a penas deslinda as feias

fauces dos grifos e se refrata:

onde se lê leia-se.

Eu não sou quem escreve,

mas sim o que escrevo:

Algures Alguém

são ecos do enlevo."

10 Stigger, Veronica (curadora). Maria Martins: metamorfoses (catálogo). São Paulo: Museu de Arte Moderna de São Paulo, 2013. p. 128. 
çamento dos corpos $e$ impedem a sua confusão total - e é justamente essa impossibilidade que a diferença de sexos na escultura marca. Na maior proximidade se revela a diferença mais intensa - ainda que infinitesimal. O que é impossível aqui é a fusão, a redução da diferença à identidade, à univocidade: e esta impossibilidade é outra condição da interlocução e da tradução, o espaço intersticial, "quase inexistente", que se abre quando dois mundos se (des)encontram.

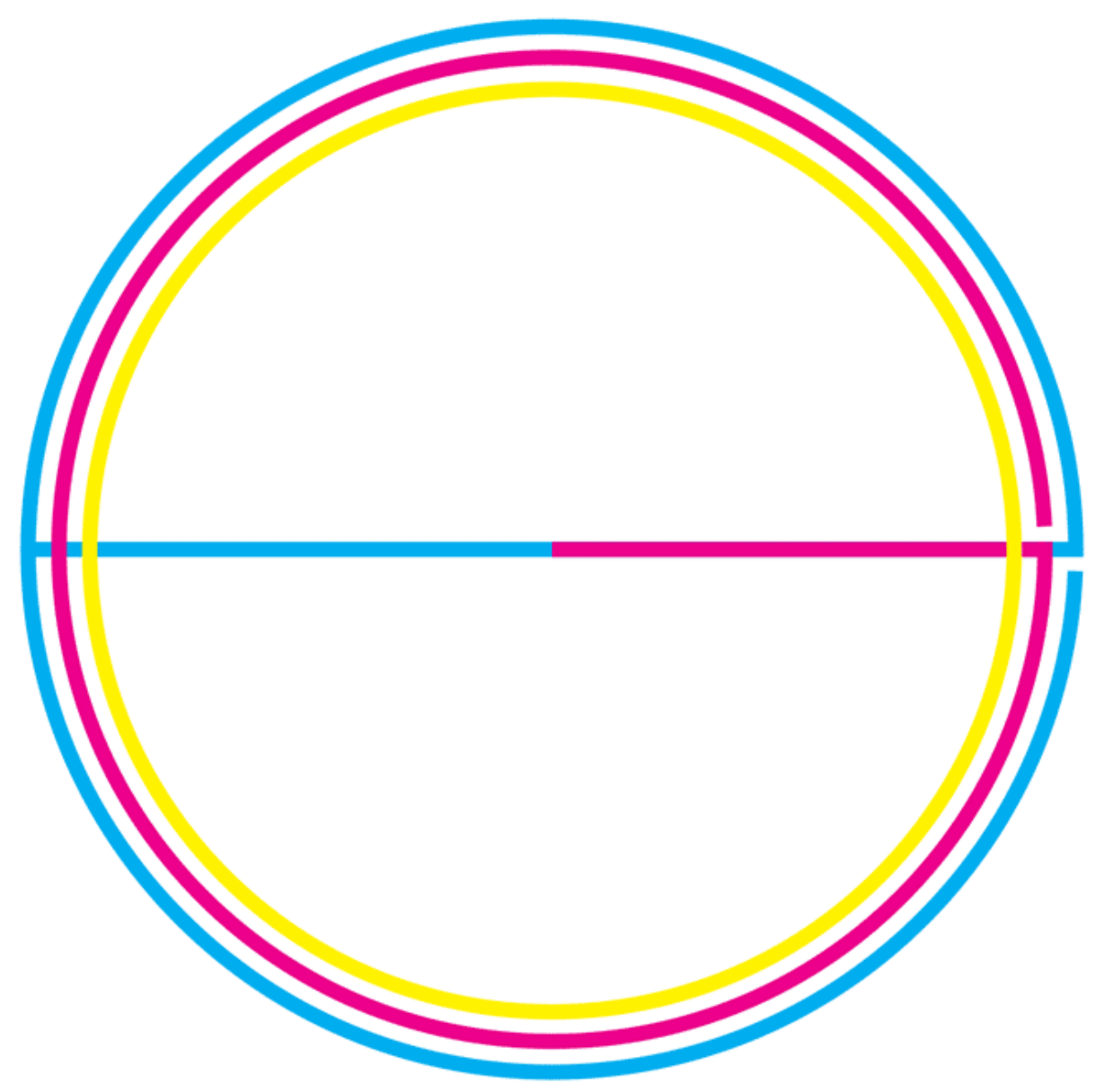

ego - André Vallias (2014) 
4. Toda interlocução, portanto, é instável, é perigosa. "O outro", diz novamente Ortega, "é formalmente, constitutivamente perigoso. A palavra é magnífica: enuncia exatamente a realidade a que me refiro. O perigoso não é resolutamente mau e adverso; pode ser o contrário: benéfico e feliz. Mas, enquanto é perigoso, ambas as contrapostas contingências são igualmente possíveis. Para sair da dúvida é preciso prová-lo, ensaiá-lo, experimentá-lo. Isso - prova, ensaio - é o que primeiro significou o vocábulo latino periculum, de onde vem (...) o nosso perigo. Observe-se, de passagem, que o radical per de periculum é o mesmo que anima a palavra experimentar, experiência, esperto, perito. (...) [O] sentido originário do vocábulo 'experiências' é: ter passado perigos" ${ }^{11} \mathrm{O}$ perigo é que a diferença de mundos se converta em hierarquia, a obliquação em assujeitamento, o mim em tu, a equivocidade em univocidade. Isso transparece naquelas teorias sobre a linguagem, como a exposta por Gabriel Tarde, em que esta teria sua origem na ordem, no comando, em que só um "eu" monopoliza a posição-sujeito ${ }^{12}$, e que talvez tenha sua expressão mais genial no estranho conto de Leopoldo Lugones, "Yzur", no qual o narrador atribui aos habitantes da ilha de Java a idéia de que os macacos "Não falam (...) para que não os obriguem a trabalhar"13. Todavia, não seria uma violência desse gênero o entendimento, que pressupõe o estabelecimento de um mundo comum, uma perspectiva única (embora relativa), em que o "eu" passa a designar apenas um ponto de tal mundo compartilhado? A tradução entendida enquanto busca de uma unidade (univocidade) na diferença (multivocidade) não seria, assim, também uma forma de violência? A violência não consistiria, em suma, na tentativa de transcender o perigo imanente a todo contato com a alteridade? Daí a importância do quase-entendimento no desencontro de que fala Clarice em nossa epígrafe, do "quase que é a única forma de suportar a vida em cheio"14, isto é, de um entendimento que é ao mesmo tempo desentendi-

\footnotetext{
${ }^{11}$ Ortega y Gasset, op. cit., p. 193-194.

12 Tarde aventa a hipótese autocrática junto com seu oposto democrático (a de que a linguagem humana teria nascido do canto, do cantar-se uns aos outros), sem decidir-se (talvez porque toda linguagem comporte ambas as dimensões) em $A$ opinião e as massas. Tradução de Eduardo Brandão. São Paulo: Martins Fontes, 2005.

${ }^{13}$ Lugones, Leopoldo. Las fuerzas extrañas. Buenos Aires: M. Gleizer, 1926. p. 133.

${ }^{14}$ Lispector, op. cit., p. 63-64.
} 
mento: uma equivocação. Pois trata-se de manter aberta a zona de passagem, "tão volátil" quanto perigosa que torna possível a tradução e a interlocução. G.H., uma alter-ego de Clarice, caracterizou essa experiência oblíqua como uma tradução não-familiarizante, em que o estranhamento não é apenas o ponto de partida, mas também o de chegada: "Precisarei com esforço traduzir sinais de telégrafo - traduzir o desconhecido para uma língua que desconheço, e sem sequer entender para que valem os sinais". ${ }^{15} \mathrm{E}$ é ela também que revela que, se o perigo da interlocução é grande, a recompensa da experiência da obliquação é ainda maior: a multiplicidade. Pois G.H. a associa com uma espécie de devir-mundo ("A despersonalização como a grande objetivação de si mesmo. A maior exteriorização a que se chega"), que é também uma subjetivação do mundo: "a vida em mim não tem o meu nome. E eu também não tenho nome, e este é o meu nome. E porque me despersonalizo a ponto de não ter o meu nome, respondo cada vez que alguém disser: eu"16 - e, poderíamos completar, todo(s) (os) mundo(s) responde(m) a cada vez que G.H. diz "eu".

\footnotetext{
${ }^{15}$ Lispector, Clarice. A paixão segundo G.H.: edição crítica. $2^{\underline{a}}$ ed. $1^{\mathrm{a}}$ reimp. Madrid: ALLCA XX, 1997. p. 15.

${ }^{16}$ Ibid., p. 112.
} 


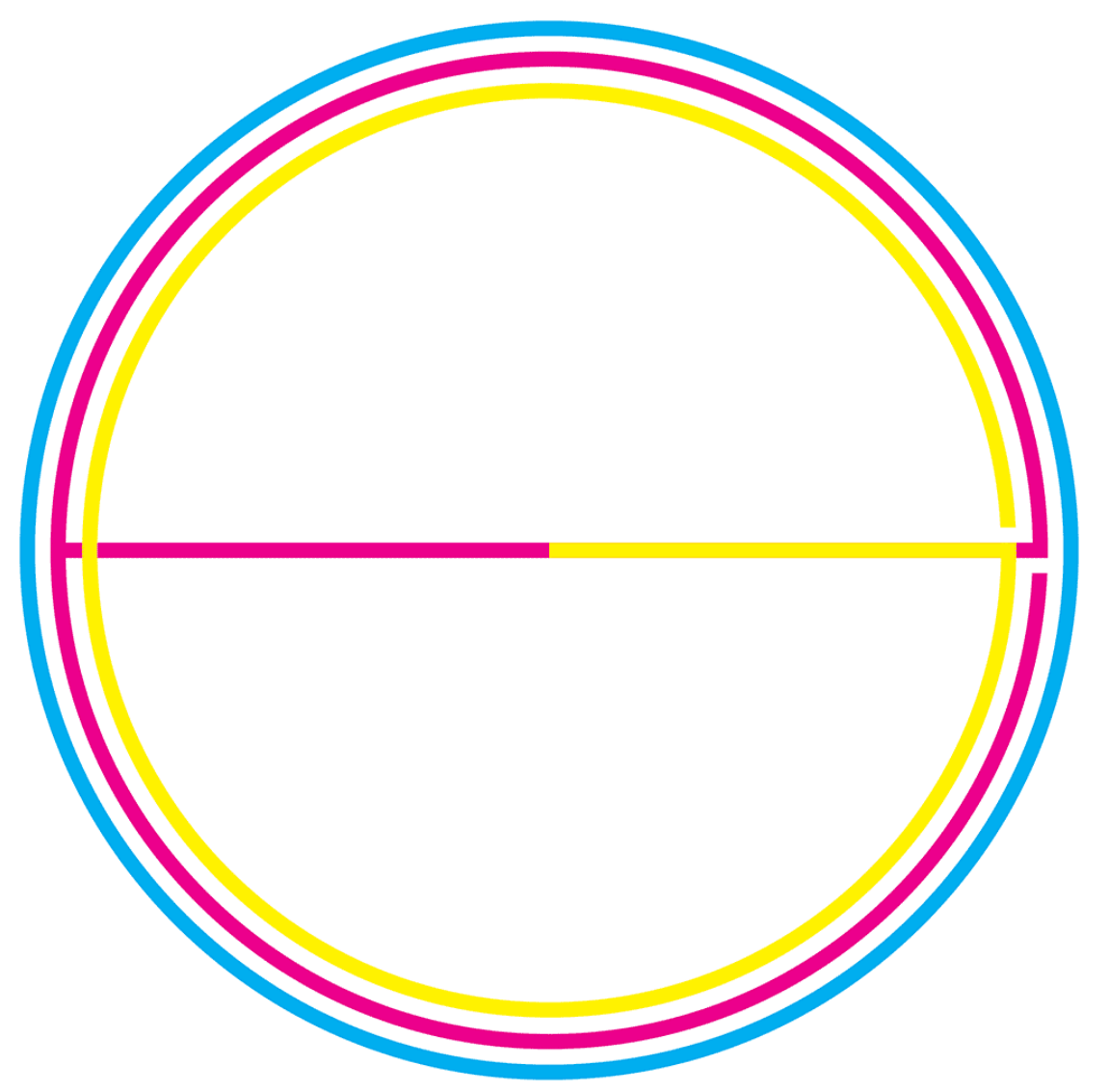

geo - André Vallias (2015)

5. Na "Introdução à obra de Marcel Mauss", Claude Lévi-Strauss identificou dois domínios do saber ocidental (seguidamente identificados ou aproximados à tradução) em que a obliquação interlocutória e tradutória atingiria sua máxima expressão: “em última instância, é uma operação do mesmo tipo que, na psicanálise, nos permite reconquistar nosso eu mais estranho e, na investigação etnológica, nos dá acesso ao mais estranho dos outros como um outro nós. Em ambos os casos, é o mesmo problema que se coloca, o de uma comunicação buscada, ora entre um eu subjetivo e um eu objetivante, 
ora entre um eu objetivo e um outro subjetivado". ${ }^{17} \mathrm{O}$ paralelo entre antropologia e psicanálise revela que o encontro com um outro eu e mesmo a interlocução - a troca posicional de quem diz "eu" -, e, por conseguinte, a tradução, começa em casa: todo ego é um oikos, a casa de um inconsciente que não cessa de tomar a posição do ego na forma do equívoco (os lapsos, os atos falhos). Dito de outro modo: não só quem diz eu é sempre outro, como também todo eu ecoa um outro. Ou melhor: outros. Pois, cada ego humano é também uma multiplicidade, um mundo: "nosso" corpo é formado por (é a casa de) infinitos corpos alheios; não só células humanas, mas também, para dar o exemplo mais evidente, um sem número de bactérias da flora intestinal. (Do mesmo modo, como revela a equivocidade Terra/terra, a nossa casa (oikos), o mundo onde moramos - a terra -, é também um sujeito, um ego, Gaia - a Terra: "o mundo é um animal extremamente sensitivo", já dizia Campanella; "o mundo é extremamente recíproco", ecoará G.H.). E essa estranheza (ou alienação, para brincar com o jargão marxista) constitutiva, o Unheimlich, a de cada "eu" ser também a casa de uma multiplicidade de outros, talvez tenha uma das suas expressões ocidentais mais interessantes na idéia estóica da oikeiosis, termo geralmente vertido por "apropriação": todo animal (incluindo aí, obviamente, o humano) passaria a vida inteira se apropriando de sua constituição, de suas partes, e, a partir daí, se apropriando daquilo que faz bem a elas e a si. Se, como diziam os estoicos, a natureza não estranha totalmente o animal de si mesmo, por que ela o constitui como próximo e próprio a si (ou pertencendo a si) e não idêntico a si? Se há proximidade ou apropriação/pertencimento e não identidade ou igualdade, então há diferença, diferença de si, diferença imanente a si. Talvez uma outra tradução, muito mais óbvia e literal, do termo oikeiosis para as línguas modernas possivelmente explique melhor o que está em jogo (e ao mesmo tempo equivoque o que entendemos por esses termos): familiarização, ou ainda melhor, domesticação. Domesticar aqui não é apenas familiarizar os outros, mas estranhar a si, outrar-se, tornar-se uma casa, um mundo, para os outros. Todo ser vivo, todo habitante terrestre, é uma rede de parentescos (internos e externos); é a construção e manuten-

${ }^{17}$ Lévi-Strauss, Claude. “Introdução à obra de Marcel Mauss". Em: Mauss, Marcel. Sociologia e antropologia. Tradução de Paulo Neves. São Paulo: Cosac Naify, 2003. p. 29. 
ção de casas: toda biologia é sempre também biografia (oikos, casa, é uma noção acima de tudo social e política) - todo eu vivente é a resultante de uma inter-locução vital. O habitat não é só uma categoria biológica, mas uma escolha (ética) vital; todo habitat é um hábito, a consistência que adquire a inter-relação da multiplicidade de seres e intensidades que habitam cada vivente. O hábito do eu é, de saída, o habitat de muitos; a vida é um "estado de contato", como dizia Clarice. Mas isso não quer dizer que a duplicidade ego/oikos implique uma harmonia, muito pelo contrário: gera ruídos, dissonâncias, ecos equívocos entre o eu e o oikos. Por isso, talvez o "erro" dos estóicos (ou da interpretação a que foram submetidos) tenha sido o de conceber a domesticação como uma via de mão única, sem atentar o suficiente para o fato de que, no gesto de traduzirmos os outros que nos constituem em um ego, estamos nos outrando, nos obliquando: se o "eu" é uma tradução dos outros, ele também é uma tradução dos outros (feita por eles). Ou, por outra: se a constituição subjetiva se dá nessa zona equívoca de ecos, nessas passagens entre o ego e o oikos, então é impossível reduzi-la a uma identidade - para dizer "eu", é preciso sempre mais (ou menos, diria Deleuze) de um, pois o "eu" é uma tradução que deriva dessa equivocidade. Toda familiarização implica, assim, um estranhamento. Nesse sentido, se a vida é uma operação de oikeiosis, uma tradução recíproca do eu e do outro, então ela é sempre uma co-domesticação, co-oikeiosis, em que a equivocidade e não a univocidade tem proeminência. A isso, creio, podemos chamar, com Guattari, de "eco-lógica", a "lógica das intensidades"18, entendendo-a como um discurso (equivocamente) ecoante, uma lógica das reciprocidades. E é nesse sentido que a tradução é uma ecologia, pois toda ecologia é também ec(h)ologia, o ressoar do eu nos outros e vice-versa, e, além disso, uma equivocologia, a mesma voz (casa), mas sempre diferente; em suma, o ecoar da equivocidade do ego, o ego ecoando equívoco o oikos que ele também é (e reciprocamente). Ego-logia, echo-logia, oiko-logia, equivoco-logia: a tradução, a interlocução, para fazer uso daquele procedimento poético de renomeação diferenciante de Glauber Rocha, Qorpo-Santo e Derrida, é uma eQologia.

${ }^{18}$ Guattari, Félix. As três ecologias. Tradução de Maria Cristina F. Bittencourt. Campinas: Papirus, 1990. p. 27. 
6. Tentando entender a permanência de uma mutação no homo sapiens que é só ocasional entre outros primatas, a esclera branca do olho ao redor da íris, pesquisadores aventaram a "hipótese do olho cooperativo": a esclera branca teria permitido melhor a leitura dos olhos entre humanos, facilitando a caça em grupo. Pat Shipman, observando que a mutação também representava um perigo (os homens, com a esclera branca, ficavam mais visíveis, especialmente no escuro, dificultando a caça e facilitando a ação de predadores), deu um passo além, conectando a hipótese a uma outra diferença dos humanos em relação aos demais primatas, a sua associação com cães, habilidoso sem ler os olhares humanos, em traduzi-los: "Outro modo de olhar esse fenômeno consiste em ver que a esclera branca se tornou universal entre os humanos porque os habilitou a comunicar melhor não só entre si, mas também com cães (...). Humanos adoram olhar nos olhos de seus cães para 'ler' suas emoções. Cães aparentemente sentem o mesmo. Talvez - e só talvez - essa comunicação recíproca foi instrumental à sobrevivência da espécie" ${ }^{19}$ Desse modo, a forma humana atual, o olhar humano tal como o conhecemos ("janela da alma", segundo uma formulação conhecida), talvez tenha sido conformado por um acidente, um equívoco mítico-biológico (uma mutação) que permitiu a nossa interlocução interespecífica com os cães. Eles teriam nos domesticado tanto quanto nós os domesticamos: codomesticação, co-oikeiosis. Tradução recíproca, com-posição de mundos: eu sou Legião, a Terra é demoníaca.

\section{Referências}

DANOWSKI, Déborah; VIVEIROS DE CASTRO, Eduardo. Há mundo por vir? Ensaio sobre os medos e os fins. Desterro: Cultura e Barbárie; ISA, 2014. DURÃO, Fábio Akcelrud. "Da superprodução semiótica: caracterização e implicações estéticas.” Em: Durão, F. A.; Zuin, A.; Vaz, A. F. A indústria cultural hoje. São Paulo: Boitempo, 2008.

\footnotetext{
${ }^{19}$ Shipman, Pat. "Do the Eyes Have It?". American Scientist, 100 (2010). p. 201.
} 
GUATTARI, Félix. As três ecologias. Tradução de Maria Cristina F. Bittencourt. Campinas: Papirus, 1990. p. 27.

HELLER-ROAZEN, Daniel. Ecolalias. Tradução de Fábio Durão. Campinas: Ed. da UNICAMP, 2010.

LÉVI-STRAUSS, Claude. "Introdução à obra de Marcel Mauss". Em: Mauss, Marcel. Sociologia e antropologia. Tradução de Paulo Neves. São Paulo: Cosac Naify, 2003. p. 29.

LISPECTOR, Clarice. Água viva. Rio de Janeiro: Rocco, 1998. p. 20. . A paixão segundo G.H.: edição crítica. 2ª ed. 1ª reimp. Madrid: ALLCA XX, 1997. p. 15.

LUGONES, Leopoldo. Las fuerzas extrañas. Buenos Aires: M. Gleizer, 1926. p. 133.

NODARI, Alexandre. "O hetairismo ontológico segundo G.H.". O eixo e a roda, 24 (2015): 139-154.

. "A literatura como antropologia especulativa". Revista da ANPOLL, 38 (2015): 75-85.

ORTEGA Y GASSET, José. O homem e a gente: inter-comunicação humana. 2. ed. Tradução de J. Carlos Lisboa. Rio de Janeiro: Livro Ibero-Americano Ltda, 1973.

PIGNATARI, Décio. Poesia pois é poesia: 1950-2000. Cotia; Campinas: Ateliê Editorial; Editora da UNICAMP, 2004.

STIGGER, Veronica (curadora). Maria Martins: metamorfoses (catálogo). São Paulo: Museu de Arte Moderna de São Paulo, 2013. p. 128.

TARDE, Gabriel. A opinião e as massas. Tradução de Eduardo Brandão. São Paulo: Martins Fontes, 2005.

VIVEIROS DE CASTRO, Eduardo. Metafísicas canibais: elementos para uma antropologia pós-estrutural. São Paulo: Cosac Naify / n-1 edições, 2015.

Resumo: Por meio de uma leitura indireta (oblíqua) de três poemas de André Vallias, pretendemos, nesse micro-ensaio, refletir sobre o estatuto da inter-locução e da tradução, concebendo-as como operações vitais de composição de mundos. Tomando a troca posicional da posição subjetiva e a equivocidade dela resultante como pontos de partida de toda relação com a 
alteridade, buscamos compreender a interlocução e a tradução como procedimentos que implicam a forma oblíqua como a primeira declinação do "eu".

\begin{abstract}
Through an indirect reading of three poems by André Vallias, we aim, in this micro-essay, to reflect on the status of interlocution and translation, perceiving both as vital operations in the building of worlds. By establishing a shift from subject to object and its resulting equivocity as the starting points of any relationship with an otherness, we seek to understand interlocution and translation as procedures which result in the object form being the first declension of "I".
\end{abstract}

